\title{
Individual, Travel, and Bus Stop Characteristics Influencing Travelers' Safety Perceptions
}

Transportation Research Record

$1-10$

(C) The Author(s) 2018

Reprints and permissions:

sagepub.com/journalsPermissions.nav DOI: I0.1 I77/036 | |98|18758677

journals.sagepub.com/home/trr

(S)AGE

\author{
Roberto F. Abenoza', Vania Ceccato², Yusak O. Susilo', \\ and Oded Cats ${ }^{1,3}$
}

Ensuring safety during door-to-door public transport trips is a fundamental challenge to service providers as safety influences individuals' mobility. Using reported safety perceptions of travelers waiting at six bus stops with different characteristics in Stockholm, this study investigates factors that have an impact on determining travelers' perceived safety and crime perceptions. This is done by assessing the importance of real-time information provision and the environmental characteristics of bus stops during the day and at night for different types of crime, after controlling for travelers' individual and trip characteristics, and their previous experiences of victimization. Interaction effects of age, gender, and travel frequency are also tested. The results suggest that bus shelter characteristics, natural surveillance, and trustworthy real-time information are the most important factors influencing safety and crime perceptions. Additionally, safety perceptions are strongly influenced by previous experiences of victimization. The effect of perceived feelings about crime and safety are found to be nuanced by age and gender. Unlike some common beliefs, travelers: (I) feel less worried about becoming a victim of crime at bus stops associated with high crime rates; (2) prefer opaque shelters at night; and (3) have higher safety perceptions when the stop is located in an area of mixed land use. The impact of a bus stop's number of passers-by is found to be insignificant. No direct or indirect effects can be attributed to frequency of travel by bus, indicating that familiar places and routine behavior have no effect on declared crime and safety perceptions.[AQ: 3]

Submission date: November 15, 2017[AQ: 1]

Safety is one of many factors influencing individuals' mobility. Ensuring safety along door-to-door public transport (PT) trips is a fundamental challenge to those responsible for providing the service. The experience of PT consists of moving times (on board and getting to and from the embarkation and disembarkation points) and waiting and transferring times. Waiting times are paramount for the entire trip as they are usually despised by travelers and have been found to be a key component when forming an overall satisfaction evaluation of a door-to-door PT journey (1). It is known that places where PT travelers spend their waiting time, including bus stops and bus stations, tend to be more criminogenic than other locations $(2,3)$.

Travelers' perceived safety is more important than actual safety in influencing perceived travel and waiting times (4) and influences travel behavior, the decision to use PT (5), travel time, and travel mode choice (6). Moreover, there is a strong link between travelers' safety perceptions and overall travel satisfaction, which in turn affects PT customer retention and recommendation. Travelers' safety perceptions have consistently been found to be amongst the most important determinants of travel satisfaction (7), and this includes the results of a particular analysis of a 13-year period (8). Therefore, it is essential to investigate how safety is perceived by travelers in waiting environments.

Previous studies $(5,3)$ have demonstrated that fear of crime, and safety perceptions are correlated with actual crime levels, the surrounding environment, and the overall design quality and features of the transport facilities. However, hitherto, there have been no scientific findings concerning the impact of bus stop factors [real-time information (RTI), the bus stops themselves, and their surrounding characteristics] on safety perceptions, in particular in relation

\footnotetext{
'Department of Transport Science, Royal Institute of Technology (KTH), Stockholm, Sweden

${ }^{2}$ Department of Urban Planning and Built Environment, Royal Institute of Technology (KTH), Stockholm, Sweden

${ }^{3}$ Department of Transport and Planning, Delft University of Technology, Delft, the Netherlands
}

Corresponding Author:

Roberto F. Abenoza, Department of Transport Science, Royal Institute of Technology (KTH), Stockholm, Sweden. [AQ: 2]

Email:rfa@kth.se 
to variations according to the time of day or night and the type of crime (property or person). It also remains unknown whether travel frequency moderates the effect of the factors.

To explore these questions, the objectives of this study are twofold. First, the paper takes a new look at the factors that might influence travelers' self-reported safety perceptions. We focus on travelers' experiences while waiting at bus stops because buses constitute the primary and most heavily used PT travel mode in many urban environments. This is done by assessing the importance of RTI provision and the environmental characteristics of bus stops during the day and at night and for different types of crime (property or person), after controlling for travelers' individual socio-demographic and travel characteristics, and their previous experiences of victimization. Second, the study aims to extend the current knowledge of how age, gender, and travel frequency moderate the effect of bus stop design, RTI, surrounding characteristics, and the impact of previous experiences of crime on safety perceptions. Obtaining the key design and information factors that minimize travelers' perceptions of being unsafe will allow stakeholders (urban and transport planners) and those responsible for the design and maintenance of bus stops to provide environments that are perceived to be safer when waiting for a bus.

This study begins by reviewing the relevant literature on crime, looking at variable aspects that influence people's safety perceptions of PT, such as socio-demographic and travel characteristics, the bus stops themselves and the type of environment that surrounds them, previous experiences of crime, and RTI. Section 3 presents the dataset and the bus stops investigated and Section 4 continues with descriptive statistics and exhibiting and discussing model estimation results. Section 5 completes this study with a discussion of policy implications, study limitations, and directions for potential future research.

\section{Literature Review}

There are several factors that affect travelers' perceived safety at bus stops. Some of them are related to the characteristics of those who fear (e.g., gender, age, disability, previous experiences of victimization), whereas others are triggered by the environment (e.g., the characteristics of the bus stop, the kind of neighborhood, the type of transportation system) or by other, less tangible factors that affect individuals' overall level of anxiety (e.g., fears about terrorism and the future). In this study we focus on two dimensions, the environment surrounding the bus stops and the travelers' individual characteristics.

\section{Travelers' Socio-Demographic and Travel Characteristics}

There is a considerable amount of evidence in the criminology and transport literature indicating that socio-demographic characteristics, such as ethnicity, income level, gender, and age, affect travelers' safety perceptions $(8-10)$. Safety is gendered and age dependent and interacts with the environment surrounding bus stops in a variety of ways. For example, feeling safe while waiting for PT was more important for women than men (11) and young women feel less safe than men when traveling by PT (12). Furthermore, Tucker (13) concluded that women and the elderly are especially fearful of crime and are more apprehensive while waiting for the bus. Women's fear was attributed to their feeling more exposed to affective crimes and also being responsible for children. Elderly people, who use bus services frequently, perceive that they are less safe (10). Yavuz and Welch (9) studied interaction effects based on gender for train trips. At peak hour, as would be expected with overcrowded railway stations, men feel safer than women. Male travelers' security perceptions are highly affected by the reliability of the service, followed by the presence of police and their previous experiences of crime. By contrast, for women, it is mainly their previous experiences of crime that affects their security perceptions, followed by the presence of police, reliability of the service, and the presence of CCTV cameras.

However, some studies did not find that age and gender had any effect on security perception with regard to PT. For example, Delbosc and Currie's (14) structural equation model showed indirect negative effects for women and elderly people through feeling safe in the home (age and gender) and in the neighborhood (age). In addition, Currie et al., (15) found that for young travelers, their safety perceptions were mainly influenced by feeling comfortable when traveling alongside people who were unknown to them. In this study, gender and actual experiences of unsafe events were found to exert a moderate effect. The relationship between gender and safety goes beyond the female-male dichotomy. Ceccato and Paz (16) indicate the need to consider safety from the perspective of those who are potentially more targeted on PT, such as the lesbian, gay, bisexual, trans, and queer community, as recent research shows that gay and transgendered persons are more often targets of harassment and violence on PT.

Very few studies have been published with a focus on the influence of travel characteristics, such as trip purpose or travel frequency, on crime and safety perceptions. Nothing has been found on trip purpose and the very little found on travel frequency has been inconclusive. For example, Currie et al. (15), with regard to young travelers, and Yavuz and Welch (9), with regard to train passengers, found that travel frequency did not affect influence travelers' safety perceptions. In contrast, the Department for Transport in the UK indicates that familiarity with an area and the transport mode are important factors that positively influence perceived safety. In other words, those who frequently use PT feel safer than infrequent users (17). In addition, Wallace et al. (18) demonstrated that travelers who used PT more frequently were more likely to notice transport security measures, thus, indirectly feeling safer. 


\section{Bus Stop Design: Environmental Characteristics}

Travelers' declared perceived safety at bus stops depends on multiscale environmental and temporal features that take effect when they leave their starting point of their trip. Yet, there are particular sites (such as bus stops and bus stations) that shape travelers' safety perceptions because people spend a considerable amount of time at or in them when traveling. The international literature has long shown that the environmental features of these sites are bound to affect travelers' perceived safety (13). This implies that environments can be planned in a way that reduces the possibility of crime occurring and improves overall perceived safety. In this line of thought, Crime Prevention Through Environmental Design (CPTED) suggests that "the proper design and effective use of the built environment can lead to a reduction in the fear of crime and the incidence of crime, and to an improvement in the quality of life" (19). CPTED points out certain environmental principles that when used in design can stimulate natural surveillance, foster territoriality, and reduce areas of conflict by controlling access. Corroborating CPTED principles, Tucker's review (13) indicates that there are several features of bus stops that contribute to increasing travelers' security perceptions. These include: shelters, benches, lighting, location, surrounding environment, design, maintenance and cleanliness of the bus stop, number of people waiting and passing by, the amount of time waiting, monitoring of the bus stop (CCTV), and the access provided to and from it.

Travelers' declared perceived safety is also affected by what happens at bus stops and in surrounding areas. Many people can be concentrated at bus stops, which makes it easier for offenders to commit crime, and bus stops can potentially pull motivated offenders toward them by the types of environments they offer $(2,3,20)$. Liggett et al. (3) found that, in the United States, opaque shelters, litter, and bus stops located in or near empty areas and close to liquor stores, pubs, and establishments for adults led to a higher incidence of crime. With regard to metro stations in Stockholm, Ceccato et al. (11) found that around half of the variation in travelers' perceived safety concerns was explained by the environmental conditions at underground stations and conditions in the surrounding areas. Unsafe underground stations were associated with visible social disturbance in lobbies, poor surveillance, higher rates of violence, and more public disorder. In turn, safe underground stations had effective formal social control-CCTV cameras or presence of guards - and had a high potential for promoting natural surveillance.

Yet, crime does not happen at random at bus stops. Crime tends to follow individuals' daily rhythmic patterns of activities, and crime may just occur in a particular area and at a time when a potential offender is aware of an opening. According to routine activity theory (21), for a crime to happen at a bus stop, some conditions must be in place: a motivated offender, a potential victim, and a lack of controllers (bouncers, guardians, and place managers).[AQ: 4] If the target is an individual, then guardians can be other passengers who are at the same bus stop. Place managers can be, for example, shop managers whose premises happen to be just in front of the bus stop and who are able to watch what happens there. In general, crimes can be categorized into property and person (22). The main difference between them is that the former involves violence aiming to acquire anything tangible, such as belongings or money (theft), whereas the latter has an emotional component and includes assault, murder, disorder, and rape.

Risk with regard to crime and travelers' perceived safety varies temporarily, hourly, daily, weekly, and seasonally (20). On top of light conditions and day or night time hours, peak hour periods, specifically, are characterized by larger flows of travelers (targets) with more potential guardians than off-peak hours. Therefore, declared safety at bus stops may reflect several other conditions experienced along the trip in a diverse array of transit environments during daily activities (23). These conditions are bound to have an effect on travelers' perceived safety.

\section{RTI and Previous Experiences of Victimization[AQ: 5]}

Some authors have partially explored how RTI variables affect safety and crime perceptions. Dziekan and Kottenhoff (24) synthesized a series of benefits attributed to at-stop RTI. Amongst these, the most relevant for this study were: perceived reduced waiting time; travel behavior adjustment; travel mode choice; and positive psychological effects that led to an increased perception of personal safety. Zhang et al. (25) concluded that travelers' safety perceptions and overall travel satisfaction increased when RTI was introduced at bus stops, and RTI available through handheld devices showed similar effects. For example, the results of a trial implementation of mobile RTI in Seattle showed that travelers' feel safer, experience reduced waiting times, are more satisfied with their trip, and increase their weekly ridership (26). In turn, Brakewood et al. (27) determined that in addition to the improvement in travelers' perceptions of their waiting time, stress and anxiety were reduced and their sense of personal safety was increased. Moreover, thanks to RTI, travelers' safety perceptions increased during the day with regard to the control group. However, no significant differences with regard to travelers' security perceptions were found at night.

Fear of crime has been studied widely. In an in-depth review (28), some evidence was found that previous experience of direct crime does not have a strong relationship with fear of crime (crime and safety perceptions). In contrast, hearsay, media and crime experienced by acquaints exert an impact on these perceptions (28). [AQ: 6] However, Teseloni and Zarafonitou (29) demonstrated that previous experience of direct and indirect crime is associated with feeling unsafe 
when walking alone at night. In addition, they found that people who were more exposed to crime by living either in criminogenic areas or by being more active in their day-today life (commuters) were more prone to feeling victimized. Furthermore, Quann and Hung (30) showed that the relationship between victimization, safety, and perceptions of crime varies according to crime type (person or property).

\section{Hypotheses of Study}

Taken together, the existing literature suggests that individual and environmental factors have an impact on travelers' declared perceived safety at bus stops. For the purposes of this study, we follow the recent strand of Western research on perceived safety in PT environments and hypothesize that perceived safety at bus stops is related not only to the environmental conditions at the bus stop itself but also to its surroundings, such as land use, socio-economic conditions, and the particular city context. Travelers' individual characteristics are also expected to affect perceived safety. Therefore, this study will test the following set of hypotheses:

(1) Assuming CPTED principles, travelers' perceived safety is reduced by bus stops with poor capacity to promote natural surveillance (opaque surface, low traffic density, few passers-by, poor PT service). Their perceived safety is affected negatively at bus stops that are crime attractors or generators (more criminogenic). Equally important are the bus stop surroundings. Travelers' perceived safety is affected by the surroundings at bus stops and mixed land use is more criminogenic than other land use types.

(2) Travelers' individual characteristics also matter in determining declared perceived safety levels. It is expected that women will declare feeling less safe than men. Passengers who have been victimized by crime tend to declare feeling less safe at bus stops than those who have not been a victim of crime.

(3) Frequency of travel from the bus stop should have an impact on safety and crime perceptions. Those who are frequent bus users and who are familiar with the schedules, the security measures of the stop, and the characteristics of the environment will be more satisfied with their safety (familiarity).

\section{Methodology And Survey Description}

A hardcopy survey was designed to evaluate travelers' safety perceptions at different bus stops. The survey was carried out in autumn 2016 with a random sample of 123 travelers who waited at six different bus stops in Stockholm. No significant events were reported during the data collection that could affect the survey results. After the dataset was cleaned and verified for completeness, 108 samples were kept. Out of the 108 , almost $75 \%$ were collected at three of the bus stops (Arkitektur-Moderna museet, Barnängen, and Mariatorget).
The remaining 29 respondents were waiting at the three remaining stops (Hötorget, Erstagatan, and Slussen). The bus stops were selected on the basis of all being located in inner city areas but varying in their environmental characteristics such as land use, number of passers-by, and crime counts. The stops also differ as far as their service characteristics are concerned, characteristics such as design, frequency of service, and passenger volumes.

The survey included questions related to the travelers' safety perceptions (general, during the day and at night) for different types of crime (person and property), previous experiences of crime, socio-demographic and travel characteristics, and travel information and planning-related issues variables. The questionnaire was designed so that it could be completed in approximately $5 \mathrm{~min}$.

With regard to studying the factors that influence safety perceptions at bus stops, the following variables were employed:

- Socio-demographic and travel characteristics: gender; age; children in the household; marital status; frequency of travel from the given bus stop; and travel purpose.

- Safety perceptions: feeling safe in the vicinity of or at the bus stop (safe day); feeling safe at night in the vicinity of or at the bus stop (safe night); and worried about becoming a victim of violence (crime person) or theft (crime property) in the vicinity of or at the bus stop.

- Previous victimization: ever having been a victim of a crime (victim crime); having been a victim of theft during the past two years (victim theft); having been a victim of violence during the past two years (victim violence); and knowing anyone, either family or friends, who has been victim of a crime during the last two years (family).

- Travel information and planning-related issues: planning the trip so as to spend as little time as possible at the bus stop (plan stop); trusting RTI displayed on the panels (trust info); feeling safer when RTI shows that the bus will arrive soon (real time soon); and feeling safer because of RTI (real time presence).

In addition to the aforementioned variables that were collected in the survey, the following variables were also included in the survey and were specified based on site visits, geographical information system tools, and PT service information:

- Characteristics of the immediate bus stop surroundings: crime rate and number of passers-by — high or low; land use - mixed or other (commercial or residential).

- Bus stop characteristics: presence of shelter; natural surveillance and presence of CCTV; frequency of service at bus stop; number of passers-by and road traffic level (these have the same response pattern (low/low/ low or vice versa) for the same stops and, thus, are interchangeable). 
Table I. Summary Statistics of Sample Profile.

\begin{tabular}{|c|c|c|c|}
\hline & Gender & Female (Male) & 42.6 \\
\hline \multirow{7}{*}{$\begin{array}{l}\text { Socio-demographic and travel } \\
\text { characteristics (\%) }\end{array}$} & Age & $<30$ & 32.4 \\
\hline & & $31-50$ & 52.8 \\
\hline & & $>50$ & 14.8 \\
\hline & Children in the household & Yes (No) & 41.7 \\
\hline & Marital status & Single* & 52.8 \\
\hline & Frequency trip & Frequent (weekly) & 73.2 \\
\hline & Travel purpose & Commuting* & 53.7 \\
\hline \multirow[t]{4}{*}{ Safety perceptions (mean) } & Safe day & & 4.15 \\
\hline & Safe night & & 3.83 \\
\hline & Crime person & & 2.71 \\
\hline & Crime property & & 2.81 \\
\hline \multirow[t]{4}{*}{ Previous experiences of crime (\%) } & Victim crime & Yes (No) & 25 \\
\hline & Victim theft & Yes (No) & 9.3 \\
\hline & Victim violence & Yes (No) & 13 \\
\hline & Family & Yes (No) & 23.1 \\
\hline \multirow{4}{*}{$\begin{array}{l}\text { Travel information available and } \\
\text { planning-related issues (mean) }\end{array}$} & Plan stop & & 4 \\
\hline & Trust info & & 3.96 \\
\hline & Real time soon & & 4 \\
\hline & Real time presence & & 3.91 \\
\hline \multirow{3}{*}{$\begin{array}{l}\text { Characteristics of the surrounding } \\
\text { area }(\%)\end{array}$} & Crime rate & High (Low) & 44.4 \\
\hline & Passers-by & High (Low) & 48.1 \\
\hline & Land use & Mixed* & 56.5 \\
\hline \multirow[t]{4}{*}{ Characteristics of the bus stop (\%) } & Natural surveillance & Good (Bad) & 51.9 \\
\hline & Shelter & Opaque (Transparent) & 21.3 \\
\hline & Service frequency & High $<10$ min in peak time (Low) & 48.1 \\
\hline & CCTV & Yes (No) & 14.8 \\
\hline
\end{tabular}

NOTE: *Other.

The scale of measurement of travel information, planningrelated issues, and safety perceptions is a Likert scale from 1 (completely disagree) to 5 (completely agree). Safety perceptions, previous experiences of crime, and bus stop characteristics variables are defined as dummy variables. Natural surveillance was assessed by considering aspects such as direct view, the view from the outside toward the inside of the bus shelter, lighting at the location, and objects obstructing a direct view. Following Loukaitou-Sideris et al. (31), the crime rate at bus stops is calculated by normalizing crime counts by the yearly ridership per bus stop. The threshold between high and low crime rate was based on quantile classification and set to 250 boarding passengers per crime.

\section{Analysis And Results}

\section{Descriptive Analysis}

Table 1 presents the summary statistics of the sociodemographic and travel characteristics, safety perceptions, prior experiences of crime, relevance of available travel information and planning-related issues, characteristics of the bus stop, and the characteristics of the surrounding area. In some cases, the data is shown as the percentage of respondents by category (\%), whereas for the Likert scale variables the mean is shown. Variables shown with an asterisk have "other" as the alternative response category. For the remaining nominal variables the alternative response category is shown in brackets.

About half of the respondents are middle-aged and single and have one or more children in the household. Almost three-quarters of people in the sample travel frequently (weekly or more often) and for most of them it was a commuting trip. Not surprisingly, and in line with previous research (9), safety perceptions are higher during the day than at night. Bus stops are characterized by: transparent shelters; no CCTV surveillance; good lighting and being located along the street; no litter; no signs of vandalism; no barriers; and windows in multiple sides. Furthermore, about half of the bus stops are very well served by PT and are subject to natural surveillance. Around half of the stops are located in areas with mixed land use and have high crime rates and number of passers-by.

Every fourth respondent has either an acquaintance who has been a victim of crime or they have been a victim themselves in the past. However, amongst these, only about $10 \%$ have been subject to theft or violence in the last two years. Overall, travelers trust the RTI displayed at bus stops and in 
planning their trips so they wait for as little time as possible. In addition, travelers report feeling quite safe when RTI is displayed at bus stops and when it shows the bus is coming soon.

A $t$-test identified a significant average difference between being a victim of a specific type of offense - crime person and crime property (sig. $=0.063$ ). In addition, significant average differences were also found when comparing safe day and safe night $(\mathrm{sig} .=0.000)$. The results of the $t$-tests provide evidence that different types of offenses and safety perceptions at different types of the day should be examined individually.

\section{Safety Perception Models}

To systematically investigate both the factors influencing safety perceptions at different times of the day, and crime perceptions for different type of offenses [person (violence) and property (theft)] four regression models were estimated. The first two models specify dependent variables "safe day" for Model 1 and "safe night" for Model 2. In turn, "crime person" and "crime property" are the dependent variables of the remaining two models, M3 and M4, respectively. The model specification of all four models is composed of the same set of explanatory variables. This set of variables includes all the factors listed in Table 1: socio-demographic and travel characteristics; prior experiences of crime; travel information available and planning-related issues; characteristics of the bus stop; and characteristics of the surrounding area. Models 1 to 4 control for many factors that influence crime and safety (socio-demographic and travel characteristics) and, therefore, will allow for better identification of the most influential ones amongst them. The independent variables were tested for multi-collinearity issues, which highlighted CCTV, resulting in this being dropped from the models. As explained in Section 3, bus service frequency and road traffic levels are equivalent to passers-by and, therefore, neither were included in the models.

Models 1 to 4 are also enriched with the inclusion of and testing for interaction effects. Two-way interaction terms were included with the aim of examining whether gender, age, and travel frequency exert a differential impact on safety and crime perceptions. These base variables were selected based on the findings of previous research $(8,13)$ and tested against travel information, bus stop characteristics and characteristics of the surrounding area variables. A manual stepwise backward method was employed to keep the significant interaction effects in the model. This method consists of including, at first, main effect variables and all two-way interaction effects. Then, after checking the model output, all main effects are retained but only significant interaction effects. Several iterations are run until the models converge into a model specification that includes all main effects but only the significant interaction effects. The total number of iterations per model was five for Model 1 (crime person) and three for Models 2, 3, and 4 (crime property, safe day, and safe night).
As the dependent variables are ordinal, ranging from 1 (completely disagree) to 5 (completely agree), an ordered logit model is the most appropriate. This can be expressed as:

$$
y_{k}^{*}=X_{k} \beta+\varepsilon_{\mathrm{k}}
$$

where $y_{k}^{*}$ is the latent dependent variable of individual $k$ and $X_{k}$ is the explanatory variable set of individual $k$, which includes all the aforementioned main and interaction effects for individual $k$. Note that the intercept is dropped for identification issues. Here $\beta$ is the corresponding vector of parameters to be estimated and $\varepsilon_{\mathrm{k}}$ is the error term that is assumed to be an identically distributed logistic error term. The latent dependent variables are then associated with the observed dependent variables, $y_{k}$ (5-point Likert scale), with $m=1-5$, defined as follows:

$$
y_{k}=\left\{\begin{array}{c}
1, \text { if }-\infty<y_{k}^{*}<\mu_{1} \\
2, \text { if } \mu_{1}<y_{k}^{*}<\mu_{2} \\
\ldots \\
m, \text { if } \mu_{m-1}<y_{k}^{*}<+\infty
\end{array}\right.
$$

For each of the four models, Table 2 displays the estimated coefficients in one column (Estim.) and the significance values (Sig.) in another. Most of the significant values are at a 99\% significance level. However, the table also shows significant values at $95 \%$ and $90 \%$ confidence intervals represented by one or two asterisks respectively. The insignificant variables $(<90 \%)$ are marked with "ns". Not applicable (na) refers to the interaction terms that were found insignificant and which, thus, were not included in the models.

Table 2 shows the widely used Nagelkerke pseudo $R^{2}$ index. It is evident that all safety models have a high degree of fit, explaining between $36 \%$ (M1 crime person) and $45 \%$ (M4 safe night) of the variation in safety and crime perceptions. All models are superior to the intercept-only models according to the log-likelihood ratio test.

As expected, and in accordance with previous research (6, 9 ), female travelers feel less safe than male travelers. In contrast to some previous findings (14), travelers younger than 50 feel safer compared with older ones. Travelers with no children in the household and, thus, conceivably traveling without being in charge of anybody, are found to be less worried with regard to becoming a victim of crime in M1 (crime person). This may indicate that when traveling with children, travelers are more concerned about personal offenses because of their sense of responsibility. However, the models do not allow for determining whether this finding is gender-specific as in some previous results (13) or if it is cross-gender.

Variables related to travel characteristics, trip purpose, and travel frequency are found to be insignificant. This indicates that there are no safety benefits arising from being familiar with the stop and schedule and is in disagreement with findings showing that perceived waiting times are longer for utilitarian trips (commuters) (32). Moreover, marital status has no influence on safety and crime perceptions. 
Table 2. Safety Perception Models.[AQ: 15]

\begin{tabular}{|c|c|c|c|c|c|c|c|c|}
\hline & \multicolumn{2}{|c|}{ MI Crime Person } & \multicolumn{2}{|c|}{ M2 Crime Property } & \multicolumn{2}{|c|}{ M3 Safe Day } & \multicolumn{2}{|c|}{ M4 Safe Night } \\
\hline & Estim. & Sig. & Estim. & Sig. & Estim. & Sig. & Estim. & Sig. \\
\hline Gender (female) & 1.218 & .004 & 1.609 & 0.006 & ns & ns & $-1.086 *$ & .011 \\
\hline Children in household (no) & $-.866 * *$ & .099 & ns & ns & ns & ns & ns & ns \\
\hline Low travel frequency & ns & ns & ns & ns & ns & ns & ns & ns \\
\hline Purpose (commuting) & ns & ns & ns & ns & ns & ns & ns & ns \\
\hline Purpose (other) & \multicolumn{2}{|c|}{ Ref. value } & \multicolumn{2}{|c|}{ Ref. value } & \multicolumn{2}{|c|}{ Ref. value } & \multicolumn{2}{|c|}{ Ref. value } \\
\hline Married or living together & ns & ns & ns & ns & ns & ns & ns & ns \\
\hline Single & \multicolumn{2}{|c|}{ Ref. value } & \multicolumn{2}{|c|}{ Ref. value } & \multicolumn{2}{|c|}{ Ref. value } & \multicolumn{2}{|c|}{ Ref. value } \\
\hline Age $(<30)$ & -20.574 & .000 & -19.948 & .000 & $2.347 *$ & .029 & $2.180 *$ & .018 \\
\hline Age $(30-50)$ & -21.155 & .000 & -21.009 & .000 & $1.730 * *$ & .051 & 2.013 & .010 \\
\hline Age $(>50)$ & \multicolumn{2}{|c|}{ Ref. value } & \multicolumn{2}{|c|}{ Ref. value } & \multicolumn{2}{|c|}{ Ref. value } & \multicolumn{2}{|c|}{ Ref. value } \\
\hline Plan stop & $-.403 *$ & .048 & $-.376 * *$ & .072 & -1.170 & .005 & ns & ns \\
\hline Trust info & ns & ns & ns & ns & $.838 *$ & .033 & $.730 *$ & .040 \\
\hline Real time soon & ns & ns & ns & ns & ns & ns & -3.098 & .000 \\
\hline Real time presence & ns & ns & ns & ns & ns & ns & ns & ns \\
\hline Victim crime (yes) & ns & ns & ns & ns & -22.378 & .000 & -21.814 & .000 \\
\hline Theft (yes) & ns & ns & ns & ns & -2.477 & .003 & ns & ns \\
\hline Violence (yes) & 2.318 & .010 & ns & ns & ns & ns & $-1.180 * *$ & .068 \\
\hline Family (yes) & $1.48 \mid *$ & .040 & ns & ns & 23.331 & .000 & 21.021 & .000 \\
\hline Crime rate (high) & -19.498 & .000 & -18.554 & .000 & ns & ns & $-3.999 *$ & .024 \\
\hline Land use (mixed) & ns & ns & ns & ns & ns & ns & 3.226 & .004 \\
\hline Land use (other) & \multicolumn{2}{|c|}{ Ref. value } & \multicolumn{2}{|c|}{ Ref. value } & \multicolumn{2}{|c|}{ Ref. value } & \multicolumn{2}{|c|}{ Ref. value } \\
\hline Natural surveillance (yes) & -16.974 & .000 & -16.498 & .000 & ns. & ns. & -4.377 & .000 \\
\hline Shelter (opaque) & 19.447 & .000 & 18.339 & .000 & $-1.726 * *$ & .082 & 1.958 & .032 \\
\hline Passers-by (high) & ns & ns & ns & ns & ns & ns & ns & ns \\
\hline$<30 *($ Crime rate $=$ high $)$ & 20.304 & .000 & 19.467 & .000 & na & na & na & na \\
\hline $30-50 *($ Crime rate $=$ high $)$ & 20.783 & .000 & 20.203 & .000 & na & na & na & na \\
\hline$<30 *($ Natural surveillance $=$ good $)$ & 16.989 & .000 & 16.843 & .000 & na & na & na & na \\
\hline $30-50 *$ Natural surveillance $=$ good & 18.429 & .000 & 19.542 & .000 & na & na & na & na \\
\hline$<30 *($ Shelter $=$ opaque $)$ & -20.928 & .000 & -21.157 & .000 & na & na & na & na \\
\hline $30-50 *($ Theft $=$ yes $)$ & $3.509 *$ & .044 & na & na & na & na & na & na \\
\hline Female* $($ Victim crime $=$ yes $)$ & na & na & na & na & $-1.945 * *$ & .076 & na & na \\
\hline$<30 *($ Family $=$ yes $)$ & na & na & na & na & -22.595 & .000 & -21.520 & .000 \\
\hline $30-50 *($ Family $=$ yes $)$ & na & na & na & na & -24.152 & .000 & -21.474 & .000 \\
\hline$<30^{*}($ Victim crime $=$ yes $)$ & na & na & na & na & 21.680 & .000 & 22.224 & .000 \\
\hline 30-50* Plan stop & na & na & na & na & 1.534 & .004 & na & na \\
\hline$<30 *$ Real time soon & na & na & na & na & na & na & 2.734 & .001 \\
\hline $30-50 *$ Real time soon & na & na & na & na & na & na & 2.564 & .002 \\
\hline Female $*$ Natural surveillance $=$ good & na & na & $-2.235^{*}$ & .015 & na & na & na & na \\
\hline \multirow[t]{2}{*}{ Female* (Shelter $=$ opaque $)$} & na & na & 3.499 & .006 & na & na & na & na \\
\hline & \multicolumn{2}{|c|}{ MI Crime Person } & M2 Crim & operty & M3 Sa & ay & M4 Saf & ght \\
\hline Log-LL zero & 339.1 & & 340. & & 264.47 & & 304.0 & \\
\hline Log-LL final & 293.0 & & 286. & & 210.21 & & 244.0 & \\
\hline Nagelkerke $R^{2}$ & & & & & .43 & & & \\
\hline$N$ & & & & & & & & \\
\hline
\end{tabular}

NOTE: Significance levels: ns = not significant; $* * 90 \%$; $95 \%$; otherwise $99 \%$ na $=$ not applicable. Estim. = estimated; Sig. $=$ significant.

Overall, RTI-related variables are insignificant, thus contradicting previous evidence $(25,26)$. The exception is the positive impact that trusting RTI displayed at bus stops has on safety perceptions during the day and at night (M3 and M4). This proves that showing trustworthy and accurate RTI to travelers is worthwhile for the effect it has on them. Interaction effects show that travelers between the ages of 30 and 50 who spend as little time as possible at the location (plan stop) tend to have higher safety perceptions.
Surprisingly, model estimation results indicate that RTI showing that the bus is coming soon negatively influences safety perceptions at night. This finding substantiates Brakewood's (27) insignificant results of RTI at night. Interaction effects unveil that feeling unsafe when RTI shows that the bus is coming soon applies only to the older traveler segment (over 50 years old). This counter-intuitive finding might be attributed to different causes - perhaps older people do not pay the same amount of attention to RTI. Alternatively, 
Transportation Research Record 00(0)

their perception of waiting time at night might be perceived as longer, considering that this age group does not use their smartphone as intensively as others and there are not many other people around to pose a distraction.

In accordance with previous research $(9,29)$, travelers who have been subject to crime in the past feel less safe at and around bus stops both during the day and at night (M3 and M4) when compared with those who have not. However, interaction effects show that this only holds true for travelers over the age of 30 and for female travelers (M3). The age effect might be explained by people feeling more vulnerable over time (33). This gender moderating effect of direct victimization on safety perceptions has already been noted by Yavuz and Welch (9). Furthermore, travelers who have been victims of theft [M3 (safe day)] and of violence (M1 and M4) have moderate higher crime and lower safety perceptions. Curiously, travelers with a family member or friend who has been a victim of crime feel safer during the day (M3) as well as at night (M4). Interaction effects, however, indicate that this only applies to those over 50. This may suggest that only direct experiences and not third-person ones influence safety perceptions of the elderly. Moreover, interaction effects show that travelers between the ages of 30 and 50 who have been victims of theft are more worried than others about becoming a victim of violence (M1). All in all, unlike Quann and Hung's (30) results, no evidence of crime-specific differences in relation to previous victimization was found.

Model estimation results suggest that not only do safety perceptions not correspond to reported crime rates, they even exercise a negative correlation. In other words, the higher the crime rate, the lower travelers' crime perceptions become [crime person (M1) and crime property (M2)]. This negative correlation concurs with several earlier research findings (20). Interaction effects, however, reveal that this is only true for travelers older than 50. At night (M4), and as expected, travelers feel less safe waiting at bus stops with high crime rates.

In line with Ceccato et al. (11), the results indicate that for crime models M1 and M2, a good natural surveillance may decrease the perception of crime. Interaction effects, however, show that this is only the case for travelers over 50 . Additionally, there is a weak negative impact on property crime perception for women (M2), which indicates that the positive influence of having good natural surveillance is greater for men. Natural surveillance also has a negative influence on safety perceptions at night (M4).

In general, opaque shelters reduce travelers' safety perceptions. This is in line with previous results (13) showing that glass or transparent shelters were preferred by travelers. However, at night, (M4) travelers feel the opposite. This might be explained by a feeling that a person is less visible. Alternatively, it might also be caused by the influence of a fishbowl effect (34), which would make people waiting at brightly lit bus stops with dark surroundings feel less safe. Interaction effects indicate that women especially are more worried about becoming a victim of theft when waiting at bus stops with opaque shelters. In contrast, travelers under 30 are much less worried about becoming a victim of person and property crimes (M1 and M2) when the bus shelter is opaque.

In contrast to earlier findings (13), many passers-by and, by extension, a frequent bus service that is close to a road with high levels of traffic, are found to be insignificant in all models. It is reasonable to think that a frequent bus service would be associated with higher perceptions of safety as travelers' exposure time to crime is reduced. At the same time, bus stops located in areas that have many passers-by and heavy traffic should also be associated with higher safety perception levels because there are more informal guardians who can prevent crime from occurring. The insignificance of these results may indicate that the differences between bus stops are too small and, therefore, the subjective thresholds between low and high are not different enough. The results may also indicate that some other important elements might have been left out of the model. For example, whereas it is true that the Arkitektur-Moderna museet stop has a infrequent bus service (and light traffic and few passers-by), there might be some other features of the surrounding built environment (in this case, a small island that is host to a several museums and hotels and linked to the mainland by a single bridge) not captured by land use, that may somehow attenuate the, in theory, negative effect on perceived safety. A mixed land use urban environment positively affects safety perceptions at night (M4), signifying that having a balanced and adequate amount of activity and of passers-by in the dark is preferred when compared with commercial and residential only land uses.

No differences across the crime models were found and this indicates that crime associated with higher levels of crowding [crime property (petty crime)] and crime associated with lower levels of crowding (crime person) do not diverge.

All in all, the interaction effects tested were mainly found to be significant with age variables, but also with gender variables. No significant interaction effects were found with frequency of travel, indicating that familiarity with PT does not play a mediating effect. In general, the estimated coefficients for the crime (M1 and M2) and safe (M3 and M4) models are consistent with regard to sign and magnitude.[AQ: 7] In addition, although main effects were very similar across crime and safe models they were significantly different with regard to the interaction terms.

\section{Conclusions}

In this study we have investigated the factors that have the greatest effect on determining travelers' perceptions of safety and crime. The analysis is based on reported safety perceptions of travelers waiting at six bus stops with different characteristics in Stockholm, at the same time controlling for a range of factors that affect these perceptions. The analysis was performed using a modest sample size and the 
generalization of the results should, therefore, be done with caution. Notwithstanding its limitations, the results of a series of OLM estimations suggest that, across the board, bus stop characteristics, natural surveillance, and trusting RTI are the most important factors influencing safety and crime perceptions.[AQ: 8] In addition, safety perceptions (M3 and M4) are highly influenced by prior direct and indirect experiences of victimization.

With regard to characteristics of bus stops (Hypothesis 1) there is a mix of anticipated and unexpected results. As hypothesized, bus stops providing good natural surveillance and transparent shelters are found to increase safety perceptions $(3,10)$. In contrast, surprisingly, travelers feel less worried about becoming a victim of any type of crime at bus stops associated with high crime rates, and no significant impact is found for the number of passers-by (traffic and bus service frequency). Mixed land use increases safety perceptions at night and the reason for this may be that bus stops located in areas where there are commercial and retail premises (stores, bars, restaurants, cinemas) have people around them at all times, promoting more guardianship.

With regard to individual attributes (Hypothesis 2), women feel less safe than men across all models. As a wealth of literature has already determined $(8,9)$, the effects of perceived crime and safety feelings are found to be nuanced by age and gender. As expected, for the safety models (M3 and M4), travelers who have had previous experiences of crime feel less safe. Contrary to expectations, the results show that no direct or indirect effects can be attributed to frequency of travel by bus (Hypothesis 3). This indicates that familiar places and routine behavior have no effect on declared crime and safety perceptions.

The finding indicating preference for natural surveillance in the form of opaque shelters at night might be addressed by introducing smart bus stops, at which the shelter color can be dimmed according to the time of day or night. The insignificant effect of travel characteristics suggests that the inclusion of these variables in perceived safety surveys can be disregarded in favor of some others that have greater effect. In general, the results of the crime models (M1 and M2) show that travelers' perceptions do not seem to be affected by crime type (person or property).

This paper provides an important understanding of all the factors that affect travelers' declared safety and crime perceptions with regard to bus stops and PT. However, there are important issues to be addressed in future studies. It would be particularly insightful to repeat this study at bus stops with even more contrasting characteristics, including a very different land use, a much different location, CCTV, RTI, lighting, litter, vandalism, windows, or existing barriers to the stop. This would allow for identifying the impact of more tangible elements that stakeholders could directly implement within the bus network to boost safety perceptions. Furthermore, different urban development and cultural contexts could be considered.

\section{Acknowledgments}

We thank Michael Boulis for his kind assistance with collecting the survey data. We also thank Oscar Willems for helping transfer data from the hard copy survey to datasheets and Nerma Muhovic for collecting data on land use and the areas surrounding bus stops. We are also indebted to the Stockholm police officer who provided the data for the analysis and to Stockholm County for providing the SLL Innovation funding that supported the authors' research activities.

\section{References}

1. Abenoza, R. F., O. Cats, and Y. O. Susilo. Travel Satisfaction With Public Transport: Determinants, User Classes, Regional Disparities and their Evolution. Transportation Research Part A, Vol. 95, 2017, pp. 64-84.[AQ: 9]

2. Smith, M. J., and R. V. Clarke. Crime and Public Transport. Crime and Justice, Vol. 27, 2000, pp. 169-233.[AQ: 10]

3. Liggett, R., A. Loukaitou-Sideris, and H. Iseki. Bus Stop-Environment Connection: Do Characteristics of the Built Environment Correlate With Bus Stop Crime? In Transportation Research Record: Journal of the Transportation Research Board, No. 1760, TRB, National Research Council, Washington, D.C., 2001, pp. 20-27.

4. Iseki, H., and B. D. Taylor. Not All Transfers Are Created Equal: Towards a Framework Relating Transfer Connectivity to Travel Behaviour. Transport Reviews, Vol. 29, No. 6, 2009, pp. $777-800$.

5. Ingalls, G. L., D. T. Hartgen, and T. W. Owens. Public Fear of Crime and Its Role in Bus Transit Use. In Transportation Research Record, No. 1433, TRB, National Research Council, Washington, D.C., 1994, pp. 201-211.

6. Loukaitou-Sideris, A., A. Bornstein, C. Fink, S. Gerami, and L. Samuels. How to Ease Women's Fear of Transportation Environments: Case Studies and Best Practices. MTI Report 09-01. U.S. Department of Transportation, 2009.

7. Abenoza, R. F., O. Cats, and Y. O. Susilo. How Does Travel Satisfaction Sum Up? Decomposing the Door-to-Door Experience for Multimodal Trips. In press: Transportation, 2017.[AQ: 11]

8. Cats, O., Abenoza, R. F., Liu, C. and Y. O. Susilo. Identifying Priority Areas Based on a Thirteen Years Evolution of Satisfaction With Public Transport and Its Determinants. In Transportation Research Record: Journal of the Transportation Research Board, Vol. 2, No. 2323, TRB, National Research Council, Washington, D.C., pp. 99-109.

9. Yavuz, N., and E. W. Welch. Addressing Fear of Crime in Public Space: Gender Differences in Reaction to Safety Measures in Train Transit. Urban Studies, Vol. 47, No. 12, 2010, pp. 2491-2515.

10. Levine, N., and M. Wachs. Bus Crime in Los Angeles: Victims and Public Impact. Transportation Research Part A, Vol. 20, No.4, 1986, pp. 285-293.

11. Ceccato, V., A. Uittenbogaard, and R. Bamzar. Security in Stockholm's Underground Stations: The Importance of Environmental Attributes and Context. Security Journal, Vol. 26, No.1, 2013, pp. 33-59.

12. Susilo, Y. O., and O. Cats. Exploring Key Determinants of Travel Satisfaction for Multi-Modal Trips by Different Travellers' Groups. Transportation Research Part A, Vol. 67, 2014.[AQ: 12] 
13. Tucker, L. E. Safer Stops for Vulnerable Customers. Final Report. NCTR-473-13. Center for Urban Transportation Research at the University of South Florida, Tampa, Fla., 2003.

14. Delbosc, A., and G. Currie. Modelling the Causes and Impacts of Personal Safety Perceptions on Public Transport Ridership. Transport Policy, Vol. 24, 2012, pp. 302-309.[AQ: 13]

15. Currie, G., A. Delbosc, and S. Mahmoud. Factors Influencing Young Peoples' Perceptions of Personal Safety on Public Transport. Journal of Public Transportation, Vol. 16, No. 1, 2013, pp 1-19.

16. Ceccato, V., and Y. Paz. Crime in Sao Paulo's Metro System: Sexual Crimes Against Women. Crime Prevention and Community Safety, Vol. 19, No. 3-4, 2017, pp. 211-226.

17. Department of the Environment, Transport and the Regions. Personal Security on Public Transport for Operators. Why Personal Security? TSO, London, 1996.

18. Wallace, R. R., D. A. Rodriguez, C. White, and J. Levine. Who Noticed, Who Cares? Passenger Reactions to Transit Safety Measures. In Transportation Research Record: Journal of the Transportation Research Board, No. 1666, TRB, National Research Council, Washington D.C., 1999, pp. $133-138$.

19. Crowe, T. D. Crime Prevention Through Environmental Design. 2nd ed. Oxford: Butterworth Heinemann, 2000.

20. Ceccato, V. Moving Safely: Crime and Perceived Safety in Stockholm's Subway Stations. Plymouth, UK: Lexington Books. 2013.

21. Cohen, L. E., and M. Felson. Social Change and Crime Rate Trends: A Routine Activity Approach. American Sociological Review, Vol. 44, No. 4, 1979, pp. 588-608.

22. Cohn, E. G., and J. Rotton. Even Criminals Take a Holyday: Instrumental and Expressive Crimes on Major and Minor Holidays. Journal of Criminal Justice, Vol. 31, No. 4, 2003, pp. 351-360.

23. Wiebe, D., T. Richmond, J. Poster, W. Guo, P. Allison, and C. Branas. Adolescents' Fears of Violence in Transit Environments During Daily Activities. In Safety and Security in Transit Environments (V. Ceccato and A. Newton, eds.), Palgrave Macmillan, London, 2015, pp. 137-155.

24. Dziekan, K., and K. Kottenhoff. Dynamic At-Stop RealTime Information Displays for Public Transport: Effects on Customers. Transportation Research Part A, Vol. 41, No. 6, 2007, pp. 489-501.

25. Zhang, F., Q. Shen, and K. Clifton. Examination of Traveler Responses to Real-Time Information About Bus Arrivals Using
Panel Data. In Transportation Research Record: Journal of the Transportation Research Board, No. 2082, Transportation Research Board of the National Academies, Washington, D.C., 2008, pp 107-115.

26. Ferris, B., K. Watkings, and A. Borning. OneBusAway: Results from Providing Real-Time Arrival Information for Public Transit. Proc., SIGCHI Conference on Human Factors in Computing Systems. Atlanta, Ga., ACM, New York, 2010, pp. 1807-1816.

27. Brakewood, C., S. Barbeau, and K. Watkins. An Experiment Evaluating the Impacts of Real-Time Transit Information on Bus Riders in Tampa, Florida. Transportation Research Part A, Vol. 69, 2014, pp. 409-422.[AQ: 14]

28. Hale, C. Fear of Crime: A Review of the Literature. International Review of Victimology, Vol. 4, No. 2, 1996, pp. 79-150.

29. Tseloni, A., and C. Zarafonitou. Fear of Crime and Victimization. European Journal of Criminology, Vol. 5, No. 4, 2008, pp. 387-409.

30. Quann, N., and K. Hung. Victimization Experience and the Fear of Crime. A Cross-National study. In Crime Victimization in Comparative Perspective. Results from the International Crime Victims Survey 1989-2000 (P. Nieuwbeerta, ed.), Netherlands Institute for the Study of Crime and Law Enforcement, Amsterdam, the Netherlands; Boom Juridische Uitgevers, The Hague, the Netherlands, 2002, pp. 301-316.

31. Loukaitou-Sideris, A., R. Liggett, and H. Iseki. The Geography of Transit Crime: Documentation and Evaluation of Crime Incidence on and Around the Green Line Stations in Los Angeles. Journal of Planning Education and Research, Vol. 22, No. 2, 2002, pp. 131-151.

32. Psarros, I., K. Kepaptsoglou, and M. G. Karlaftis. An Empirical Investigation of Passenger Wait Time Perceptions Using Hazard-Based Duration Models. Journal of Public Transportation, Vol. 14, No. 3, pp. 109-122.

33. Ceccato, V., and R. Bamzar. Elderly Victimization and Fear of Crime in Public Spaces. International Criminal Justice Review, Vol. 26, No. 2, 2016, pp. 115-133.

34. Loukaitou-Sideris, A., and C. Fink. Addressing Women's Fear of Victimization in Transportation Settings. A Survey of U.S. Transit Agencies. Urban Affairs Review, Vol. 44, No. 4, 2009, pp. 554-587.

The Task Force on Transit Safety and Security peer-reviewed this paper. 